\title{
The X-Ray-TV Investigation of Behaviour of a Bismuth Sample Introduced to Molten Steel
}

\author{
Andrey V. Ryabov ${ }^{1}$, Alexander M. Panfilov ${ }^{2} \&$ Natalya S. Semenova ${ }^{2}$ \\ ${ }^{1}$ South Ural State University, 76, Lenin prospekt, Chelyabinsk, 454080, Russian Federation \\ ${ }^{2}$ Ural Federal University Named After the First President of Russia B.N. Yeltsin, 19 Mira street, Ekaterinburg, \\ 620002, Russian Federation \\ Correspondence: Andrey V. Ryabov, residential block Molodezhnaya, 86-8, Chelyabinsk region, Zlatoust, 456200, \\ Russian Federation. Tel: 7-964-244-4242. E-mail: andrey_v_ryabov@mail.ru
}

Received: November 21, 2014 Accepted: November 27, 2014 Online Published: January 15, 2015

doi:10.5539/mas.v9n2p244 URL: http://dx.doi.org/10.5539/mas.v9n2p244

\begin{abstract}
The study is devoted to the processes accompanying introduction of bismuth to molten steel. Two variants of such introduction were used, viz. bismuth granules and bismuth contained in a steel tube. The time of tube melting, the behaviour of granules and droplets of bismuth and of the gas bubbles formed at their surfaces in the steel melt are discussed. Experiments were carried out with the $0.4 \mathrm{C}-1 \% \mathrm{Cr}$ steel melt at $1550-1580{ }^{\circ} \mathrm{C}$ by means of the X-ray - TV observation. Based on image analysis the volumes of droplets and bubbles were estimated as a function of time. Arguments are provided to support the supposition that the bubbles of bismuth vapour in steel melt are enveloped by liquid metal. Estimates of the horizontal constituent of velocity of bismuth droplets in inhomogeneously heated steel presumably permitted to observe the thermocapillary effect previously found in some other systems. Simultaneous evaluation of the volume of bismuth droplets and forming bubbles and of the contact area of the phases permitted to estimate the specific rate of evaporation of bismuth to the bubble of its own vapour at $1580^{\circ} \mathrm{C}$. It was found to be several orders of magnitude lower than that of evaporation of bismuth into vacuum.
\end{abstract}

Keywords: bismuth, molten steel, x-ray-TV investigation

\section{Introduction}

Bismuth is coming into use to replace lead in free-cutting steels for environmental reasons (Ryabov and Chumanov, 2012). Like lead, bismuth has very low solubility in the iron-carbon melt and is present in solid steel in the form of disperse inclusions contributing to good machinability of parts. However, bismuth is more difficult to introduce into steel than lead due to its lower boiling temperature (only 28 degrees above the melting temperature of pure iron). So special investigation is required to develop a technology of alloying steels with bismuth.

\subsection{Literature Review}

There are few works concerning bismuth behaviour in a steel melt, since the interest to this element as a machinability enhancer has arisen not long ago.

Free-machining steels are utilized in machine building to increase the performance of cutting machines, save cutting tools, achieve high quality of machined surface, increase cutting speed and mechanize the removal of chips. These steels contain alloying elements like sulfur, phosphorus, lead, selenium, tellurium, boron, bismuth, calcium, or untraditional elements like indium, tin or uranium, or combinations of those (Cai et al., 2011, Han et al., 2013, Li et al., 2013, Shinozuka et al., 2012, Zhang T., 2013, Zhang et al., 2012, Zhuang et al., 2012).

Alloy additions used to increase machinability are divided into four groups (Zaslavskii, 2005). The first one includes elements affecting the properties of $\alpha$ or $\gamma$ solid solution matrix (phosphorus and nitrogen). Elements of the second group affect metal properties through formation of non-metallic inclusions (sulfur, selenium, tellurium) (Xu J., An Q., Chen M., 2012). Third group elements (calcium and barium) transform non-metallic inclusions already formed before. And the influence of the elements of the fourth group consists in creating metallic inclusions of their own - lead, bismuth. Different additives have different effect on machinability, and each of them has an optimal area of application as well as some advantages and shortcomings (Zaslavskii, 2005, Maekawa et al., 2001). 
Sulfur- and phosphorus-containing steels have been used for increasing machinability since the second decade of the XX century. Sulfur is used in corrosion-resistant and structural carbon and alloy steels (Wu and Li, 2012). But high-sulfur and high-phosphorus free-machining steels could not find a wide use due to low level of mechanical properties (Shu et al., 2014.). In 1930s a need for increasing productivity of machine building attracted the metallurgists' attention to steels containing lead. Lead, unlike sulfur and phosphorus, does not impair mechanical properties of steel, and at the same time raises machining productivity by $20-50 \%$ and tool life $2-3$ times, and improves surface quality. In 1950-60s selenium and tellurium also came into use to improve machinability. But the production of steels containing lead, selenium or tellurium has one key disadvantage, namely extreme toxicity of these elements. In addition, selenium and tellurium are very expensive.

Attempts to replace lead-bearing steels have lead to development of lead-free free-machining steels containing boron. Boron is a non-toxic environmentally friendly element, but machinability of boron steels achieves that of leaded steels only at outer cutting (Reh et al., 1979, Reh et al., 1982). Another element applied to increase steel machinability is bismuth. Maximum permissible concentration of bismuth in the working area is $0.50 \mathrm{mg} / \mathrm{m}^{3}$ compared to $0.01 \mathrm{mg} / \mathrm{m}^{3}$ for lead (Filov, 1989, Filov, 1988). Replacing of lead with bismuth thus gives a chance to abandon the use of high-cost devices necessary to accumulate lead vapour and oxides.

Free-machining steels with bismuth are mainly produced in the countries with well-developed automobile industry: Japan, USA, China, Korea, UK, European Union (Germany, Italy, France etc.).

Bismuth-bearing steels are used to produce critical high-strength parts, especially those for which the production performance is limited by machining operations like drilling, milling or gear-cutting and high accuracy of machining operations is required. In this case the addition of bismuth is beyond comparison with other ways of increasing steel machinability.

According to the current literature, the interest towards environmentally friendly free-cutting steels without lead, including the bismuth-bearing steels, is steadily increasing. Beside structural steels, bismuth is added as a machinability enhancer to ferritic and austenitic corrosion-resistant, heat-resistant, wear-resistant, tool and bearing steels (Li et al., 2013, Li et al., 2012). Such steels contain from 0.01 to 0.40 , and sometimes up to $0.60 \mathrm{wt}$. pct bismuth.

At present, low-melting point alloying elements like bismuth are usually added to steel during pouring. But high vapour pressure and low solubility of bismuth result in its unstable recovery, and thus more detailed investigation of the behaviour of bismuth in steel melt is required. This can be done, for example, by means of X-ray - TV observation (Panfilov et al., 2002).

\section{Materials and Methods}

Experiments were carried out with a controlled-atmosphere high-temperature device with an X-ray - TV observation system installed at the Theory of Metallurgical Processes Department of the Ural Federal University. A detailed description of this device is given in (Panfilov et al. 2002). To carry out this investigation some thermal insulation materials were replaced and the distance between the object (corundum crucible containing the melt) and the X-ray tube was reduced in order to increase the radiation intensity. Of course, this reduced the image definition because of increase of penumbra. The focus spot diameter of the available device was about $2 \mathrm{~mm}$. But increased intensity and some methodical enhancements like screening the bright parts of the image with lead plates located outside the furnace permitted to observe bismuth samples above $1 \mathrm{~mm}$ in diameter in the volume of steel melt with the thickness of $15 \mathrm{~mm}$. Software used to draw information from an X-ray - TV image has also been significantly upgraded.

Spherical bismuth samples with a mass of $0.5-1.0 \mathrm{~g}$ and steel tubes with an outer diameter of $5 \mathrm{~mm}$ filled with bismuth were used in the experiments. The tubes had been filled with liquid bismuth at about $320^{\circ} \mathrm{C}$ and their ends had been caulked. The samples were initially located in the cold area of the furnace. When the steel melt reached a temperature of about $1550^{\circ} \mathrm{C}$ the samples were dropped in it from a distance. At the same time X-ray - TV images were continuously recorded at a frame rate of $25 \mathrm{frames} / \mathrm{sec}$. Closed ends of steel tubes were half immersed in the melt and were held by the other part with a nickel thread to maintain vertical position. Molten steel of about $100 \mathrm{~g}$ covered with a $5 \mathrm{~mm}$ layer of slag consisting of $\mathrm{CaO}, \mathrm{SiO}_{2}$ and $\mathrm{Al}_{2} \mathrm{O}_{3}$ was contained in a crucible of a special shape. Horizontal section of the crucible was a $15 \times 40 \mathrm{~mm}$ rectangle, and X-rays were directed along its smallest size. The bottom part of the crucible had a shape of a truncated pyramid, and a thermocouple was placed at its base. The furnace was evacuated to forevacuum when heating to about $600{ }^{\circ} \mathrm{C}$ and then filled up with helium so that the pressure at the working temperature would be close to $1 \mathrm{~atm}$.

Each experiment yielded a series of X-ray - TV image files and a file containing the values of thermocouple 
readings and regulating parameter of the thermal regulator. Typical values of these parameters for one of the experiments are presented in Fig. 1.

Approximately two minutes after the dropping of the sample, when the recorded parameters ceased changing, the experiment was interrupted and the melt started to cool at a rate of about $150 \mathrm{deg} / \mathrm{min}$.

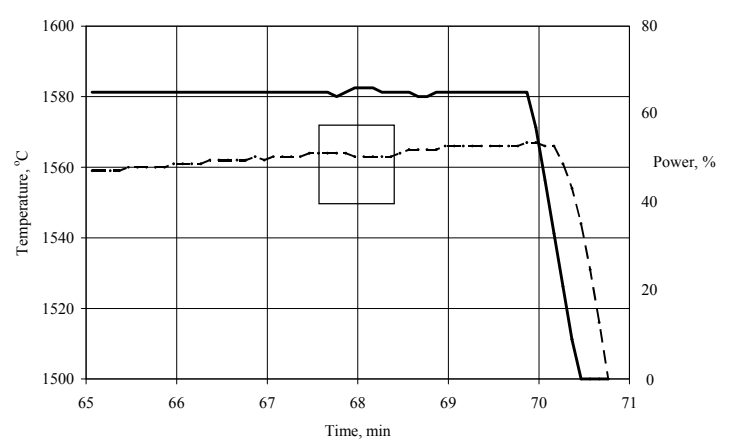

Figure 1. Time dependence of the steel melt temperature ( - - line) and the power at the heater (- - line) at the end of an experiment. The frame indicates the time interval when the X-ray - TV recording was carried out during the dropping of the sample

The objects interesting for quantitative evaluation were analyzed on each X-ray - TV image frame. Such objects were the drops of metal, gas bubbles, some parts of interphase interfaces. By means of a special program the coordinates of the points on the object surface were evaluated from the image coordinates taking account of geometric magnification coefficient and all kinds of distortions arising from several transformations of the image. Some of correction coefficients were obtained from analytical investigation of the transformations, and the others from measuring reference images.

The authors believe that this technique permitted to exclude significant systematic errors, but the random error of our experiments was rather great due to objective reasons. So the drops and the bubbles were approximately considered ellipsoids when evaluating their volume, since it was impossible to establish their true shape. The standard error of measurement of linear sizes with the present device is estimated to about $0.2 \mathrm{~mm}$.

\section{Results}

\subsection{Experiments with Bismuth Leaking from Steel Tubes}

Melting of the caulked end of a steel tube and the start of bismuth leaking from it took about 4 sec after immersing it into the melt. This time was sufficient for heating through of the sample and for melting of bismuth and some amount of steel at the end of the sample. After that bismuth started to leak from the tube forming drops $2-3 \mathrm{~mm}$ in diameter. An image of the tube and a bismuth drop approaching the bottom of the crucible is shown in Fig. 2.

Gas bubbles were not observed visually on the surface of these drops, but measurement results yielded some interesting conclusions. It was found that all drops moved along an inclined trajectory shifting from the formation point to the centre of the crucible with an average velocity of $1 \mathrm{~cm} / \mathrm{sec}$. A vertical component was not much greater and had a maximum value of $5 \mathrm{~cm} / \mathrm{sec}$. Velocities of sinking of two drops of a significantly different size as a function of their position in the crucible (i.e. depth of submersion) are shown in Fig. 3. The velocity of sinking changes nonmonotonically, i.e. the drop accelerates right after its formation and slows down near the bottom of the crucible.

It is interesting to note that the velocity of sinking does not depend on the drop diameter, though according to the Stokes formula it must differ almost fourfold.

After melting of the steel tube the source of a temperature gradient disappears and the bubbles are observed to form, grow and tear off from bismuth particles submerged in the steel melt. Because of this a bismuth particle is able not to sink for a long time moving in a regular manner as shown in Fig. 4. 


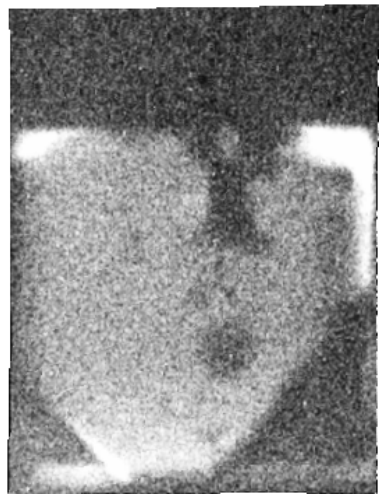

Figure 2. An image showing a bismuth drop in the steel melt and the tube from which it was formed

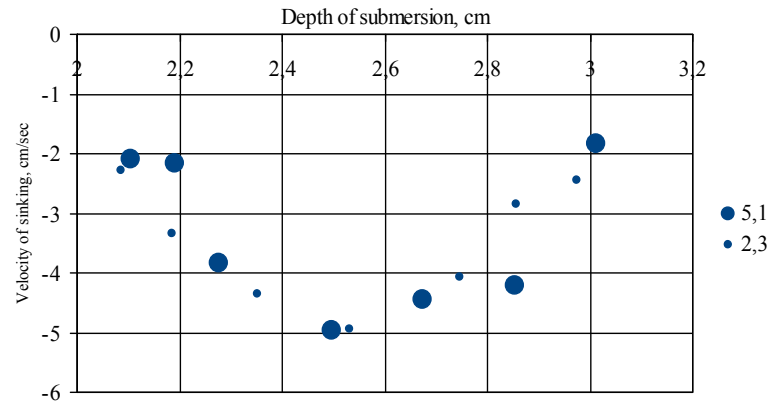

Figure 3. Velocities of sinking of two drops with different diameters (5.1 and $2.3 \mathrm{~mm}$, see legend) as a function of the depth of submersion in the melt. The bottom of the crucible is at the depth of approximately $3.2 \mathrm{~cm}$

It is easy to see from X-ray - TV images that the size of the drop decreases during this process. Fig. 5 shows the time dependence of the volume of bubbles and the drop from which they had formed. The volume of the drop was estimated in the absence of bubbles until the drop became too small for correct measurements.

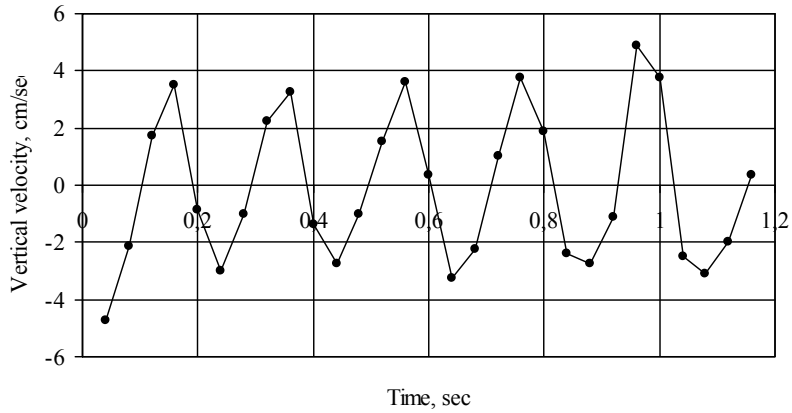

Figure 4. Periodic changes of the velocity of movement of a bismuth drop during boiling in molten steel

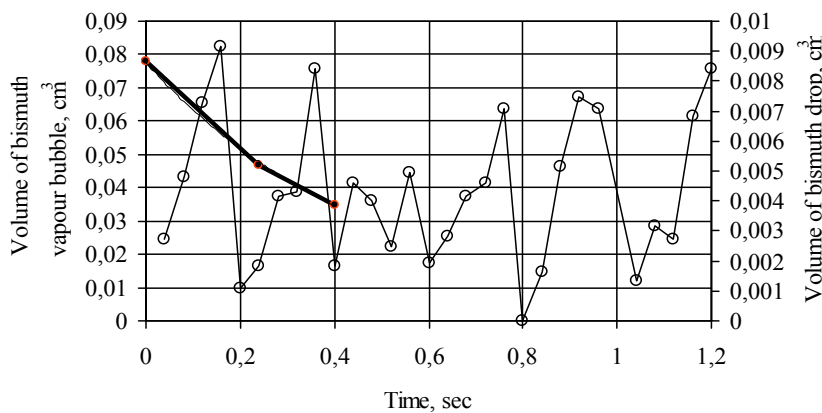

Figure 5. Changes in the volume of bubbles (open circles) and the bismuth drop during boiling

Approximately $5 \mathrm{sec}$ after the introduction of the sample a pool of liquid bismuth starts to form under the steel layer. Assimilation of bismuth by the steel melt and the gas phase above it finishes about 20 sec after the sample submersion. By the same time oscillating hydrodynamic processes in the liquid caused by the sample dropping are also almost completed.

\subsection{Experiments with Single Bismuth Samples}

In this type of experiments the cold bismuth granule reached the bottom of the crucible in the time of shooting of a single frame. A drop having the volume much greater than in previous experiments formed then at the bottom of the crucible. Already $100 \mathrm{~ms}$ later a gas bubble started to form at its surface. This means that the surface layer of the sample reached the boiling temperature of bismuth. The increased bubble passed a significantly greater distance in the melt after tearing off from the sample, so it was possible to track the change of its size. Fig. 6 shows a sequence of X-ray - TV frames illustrating this process.

It is very well seen that the volume of a gas bubble is continuously increasing even after a loss of contact with the bismuth sample. This effect can be explained neither by a change of metallostatic pressure, since the melt depth is too small, nor by a change of the radius of curvature of the bubble surface, since it is too great. A change of the bubble volume may be caused only by a change of gas moles, i.e. by evaporation. This is possible if the bubble has an envelope of liquid bismuth. 


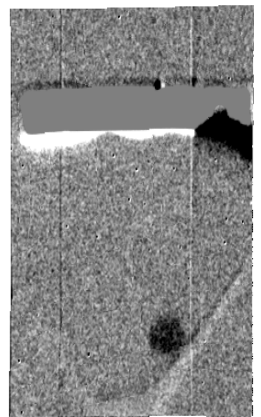

0

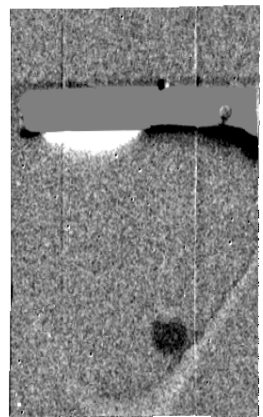

0.04

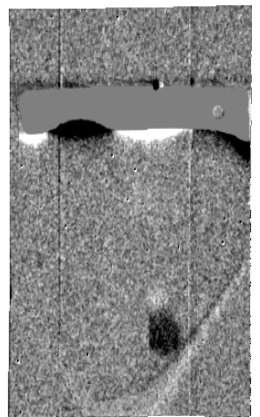

0.08

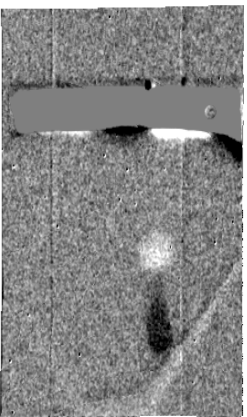

0.12

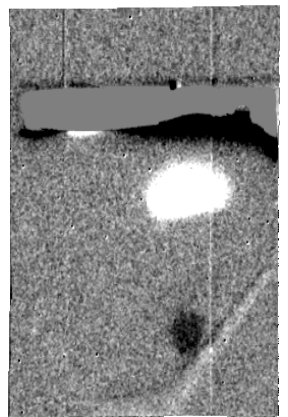

0.16

Figure 6. A series of frames showing a bismuth drop in the steel melt and a bismuth vapour bubble nucleating, growing, tearing off and leaving the melt. The figures indicate time in seconds. Steel melt temperature is $1580{ }^{\circ} \mathrm{C}$

We managed to observe two bubbles successively. The time dependence of the position of the centre of masses of the drop and the bubbles illustrating the development of the process is shown in Fig. 7.

Like in the previous case, the volume of the bismuth sample decreased with time (Fig. 8), but the volumes of the drop and the bubble can be estimated separately on each frame.

Results of measurement of the bismuth drop volume witness a great velocity of the decrease of its mass.

Assimilation of the bismuth sample by the melt and accompanying processes finished in $4-5$ sec in these experiments.

\section{Discussion}

Small velocity of sinking of bismuth drops leaked from the steel container means that most likely they are enveloped by a semi-liquid slurry of steel cooled by some tens of degrees. It is possible that the drops were simply moving with the top-down convective stream of steel since the sample was introduced cold and was continuing to heat up.

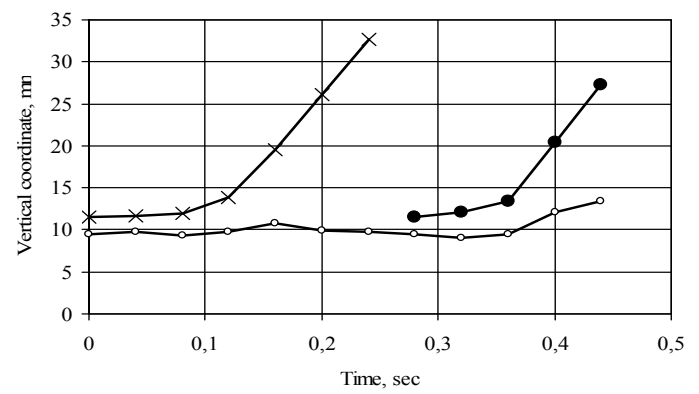

Figure 7. Change of the position of the centre of mass of the bismuth drop and the bubbles with time $(\times-1$ st bubble, - - 2nd bubble, $\circ$ - drop)

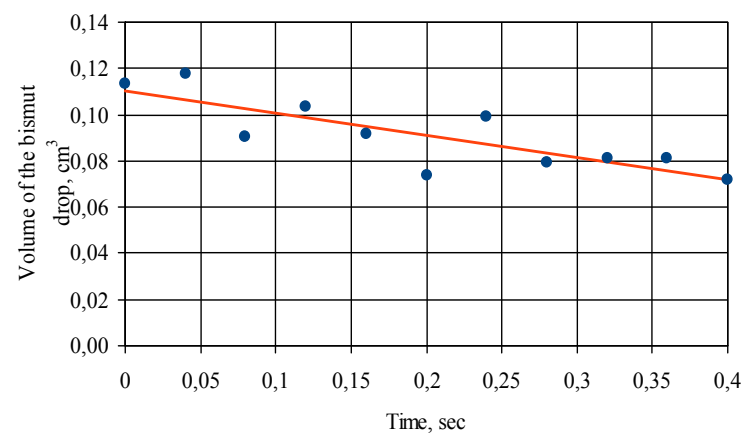

Figure 8. Dependence of the volume of a bismuth drop evaporating in steel melt on time

At the same time the drops are moving horizontally at a velocity of approximately $1 \mathrm{~cm} / \mathrm{sec}$, as if the descending 
convective stream pushed them sideways. Interphase tension at the bismuth/steel interface decreases with increasing the temperature, like in most systems. A decrease of interphase tension at the side of the drop facing the heated part of the melt results in circulating streams inside the drop and around it. These streams tend to push the drop towards a hotter area. This effect called a thermocapillary effect, is well known (Young et al., 1959, Assael et al., 2012.) and is described in many works, e.g. (Grashchenkov S.I., 1996), but it is probably its first observation in a system of immiscible liquid metals. Of course, it is to be taken into account when analyzing the processes of alloying steel with bismuth.

In spite of a small number of points it was possible to estimate an average rate of a decrease in the number of moles of bismuth in the drop based on measurements of the volume of the drop and the forming bubbles in experiments with tubular samples. This average rate was equal to $500 \mu \mathrm{mole} / \mathrm{sec}$. To estimate bismuth density an empirical equation from (Alchagirov and Mozgovoi, 2003) was used, extrapolated by approximately 300 degrees above the recommended interval. During the measurement of the drop volume it decreased by $190 \mu$ mole, and two bubbles with an overall volume of $0.16 \mathrm{~cm}^{3}$ tore off from it. Considering the gas ideal, the amount of bismuth passed to the vapour can be estimated as $1 \mu$ mole.

Thus the decrease in the amount of bismuth in the drop is not caused by evaporation. It is also evident that bismuth cannot dissolve in the melt so fast since its solubility in steel is extremely low. It remains to suppose that each bubble captures some amount of liquid bismuth. The liquid is most likely distributed on the surface of a bubble as a thin envelope. It is known that surface tension of liquid bismuth is very small. Direct measurements in the inert gas atmosphere give $374 \mathrm{~mJ} / \mathrm{m}^{2}$ near the melting point and $350 \mathrm{~mJ} / \mathrm{m}^{2}$ at a temperature 200 degrees higher (Ceotto, 2013). If this tendency holds, then a value of about $250 \mathrm{~mJ} / \mathrm{m}^{2}$ can be expected at the temperature of our experiment. No data is available on the interphase tension at the bismuth/steel interface, but it cannot be much greater than surface tension. A meniscus shape of the bismuth/steel interface, which we observed when a pool of bismuth formed at the bottom of the crucible, is an evidence of it. Then it may be supposed that a sum of surface tension of bismuth at the interface with its own vapour $\left(\sigma_{\mathrm{Bi}}\right)$ and interphase tension at the bismuth/steel interface $\left(\sigma_{\text {Bi-steel }}\right)$ is smaller than the surface tension of steel $\left(\sigma_{\text {steel }}\right)($ Eq. 1):

$$
\sigma_{\mathrm{Bi}}+\sigma_{\mathrm{Bi} \text {-steel }}<\sigma_{\text {steel }}
$$

If this condition of complete wetting is fulfilled, the formation of a liquid bismuth envelope on the surface of a gas bubble is favourable.

The conclusion of the presence of a liquid bismuth envelope on the surface of bubbles was also confirmed by experiments with bismuth balls dropped in the melt. In this case the amount of moles of bismuth in the drop decreased by $1700 \mu$ moles in $0.4 \mathrm{sec}$. During this time two bubbles tore off from it, with a total volume of $0.07 \mathrm{~cm}^{3}$ ( $0.5 \mu$ moles of an ideal gas).

Let us write the condition of mechanical equilibrium of a spherical bubble with the radius $r$ filled with $n$ moles of an ideal gas under the pressure $P$ having an envelope with the tension $\sigma=\sigma_{\mathrm{Bi}}+\sigma_{\mathrm{Bi} \text {-steel }}$ placed in the liquid with the density $\rho$ at the depth $h$ (Eq. 2):

$$
P=P_{0}+\rho g h+\frac{2 \sigma}{r}=\frac{3 R T}{4 \pi r^{2}}
$$

Here $P_{0}$ is the pressure of the furnace atmosphere. Differentiating Eq. (2) with respect to time $\tau$ and taking into account a change of $r, h$ and $n$ with time, one obtains the following equation for the specific rate of bismuth evaporation to the volume of the bubble per unit surface of the interface (Eq. 3):

$$
v=\frac{\left(P_{0}+\rho g h+\frac{4 \sigma}{3 r}\right) \frac{d r}{d \tau}+\frac{\rho g}{3} r \frac{d h}{d r}}{R T} .
$$

The values of derivatives appearing in this formula were found by numerically differentiating the results of measurement of objects in the image with three-point smoothing. To estimate the density of the steel melt a formula from (Ceotto, 2013) was used; $\sigma$ was accepted equal to $0.7 \mathrm{~J} / \mathrm{m}^{2}$. By averaging values for three bubbles it was found that the observed dependences could be described quantitatively if a specific rate of bismuth evaporation into the volume of its own gas at a pressure close to $1 \mathrm{~atm}$ and a temperature of $1580{ }^{\circ} \mathrm{C}$ is 0.3 $\mathrm{mg} /\left(\mathrm{cm}^{2} \cdot \mathrm{sec}\right)$. One may mention for comparison that according to (Kazenas et al. 1998) the rate of evaporation of pure bismuth into vacuum at its boiling temperature $\left(1564{ }^{\circ} \mathrm{C}\right)$ is $21.15 \mathrm{~g} /\left(\mathrm{cm}^{2} \cdot \mathrm{sec}\right)$. 


\section{Conclusions}

1. Very low velocity of sinking of bismuth bubbles in liquid steel is detected. It is explained by the cooling of the steel melt.

2. The effect of thermocapillary movement of liquid bismuth in steel melt was conceivably observed.

3. Evidence of the existence of foam bubbles on the surface of bismuth droplets settling in the steel melt has been shown.

4. The rate of evaporation of bismuth in liquid steel has been determined.

5. According to the study, bismuth during bottom casting of steel is to be in a gaseous state and may contribute to the formation of "subsurface bubbles" defect in the bottom part of the ingot. Therefore it is recommended that bismuth should be supplied into the centerline only after filling the molds to a height of 100-200 mm, which would increase the metal yield by $10-20 \%$.

\section{Acknowledgement}

The study was performed in the framework of the Federal Target Program "Research and Development in Priority Directions of Scientific-Technological Complex of Russia for 2014-2020” (contract No. 14.574.21.0054).

\section{References}

Alchagirov, B. B., \& Mozgovoi, A. G. (2003). Experimental Investigation of the Surface Tension of Liquid Lead and Bismuth in the Vicinity of Melting Point. High Temperature, 41(3), 412-414. http://dx.doi.org/10.1023/A:1024207114077

Assael, M. J., Kalyva, A. E., \& Antoniadis, K. D., et al. (2012). Reference Data for the Density and Viscosity of Liquid Antimony, Bismuth, Lead, Nickel and Silver. High Temperatures-High Pressures, 41, 161-184.

Cai, X. J., Liu, Z. Q., Wang, Q. C., Han, S., An, Q. L., \& Chen, M. (2011). Surface Roughness Prediction in Turning of Free Machining Steel 1215 by Artificial Neural Network. Advanced Materials Research, 188, 535-541. http://dx.doi.org/10.4028/www.scientific.net/AMR.188.535

Ceotto, D. (2013). Thermal Diffusivity, Viscosity and Prandtl Number for Molten Iron and Low Carbon Steel. High Temperature, 51(1), 131-134. http://dx.doi.org/10.1134/S0018151X13010045

Grashchenkov, S. I. (1996). The Effect of Slip on the Motion of Two Droplets and of a Droplet Close to a Plane Surface of a Liquid. Aerosol Sci. Technol., 25(2), 101-112. http://dx.doi.org/10.1080/02786829608965383

Han, J., Li, Y., Jiang, Z., Yang, Y., Wang, X., Wang, L., \& Li, K. (2013). Summary of the Function of Sn in Iron $\begin{array}{lllll}\text { and } & \text { Steel. Advanced }\end{array}$ http://dx.doi.org/10.4028/www.scientific.net/AMR.773.406

Harmful chemicals. Inorganic compounds of I-IV groups: a reference book. Ed. by V.A.Filov. Leningrad, Khimiya Publ., 1988. 512 p.

Harmful chemicals. Inorganic compounds of V-VIII groups: a reference book. Ed. by V.A.Filov. Leningrad, Khimiya Publ., 1989. 592 p.

Kazenas, E. K., Astakhova, G. K., \& Penkina, T. N. (1998). To Estimation of the Rate of Evaporation of Metals. Metally, 1, 33-40.

Li, Z., Wu, D., \& Lv, W. (2012). Application of Rare Earth Elements in Lead-Free "Green Steel". Advanced Materials Research, 518-523, 687-690.

Li, Z., Wu, D., Lv, W. Zheng, Z., \& Kang, S. (2013). Investigations on Low Environmental Impact Machining Processes of Free Cutting Austenitic Stainless Steels. Applied Mechanics and Materials, 377, 112-116. http://dx.doi.org/10.4028/www.scientific.net/AMM.377.112

Li, Z., Wu, D., \& Lv, W. (2012). Low Environmental Impact Machining Processes of Free Cutting Austenitic Stainless Steels without Lead Addition. Advanced Materials Research, 512-515, 1923-1926. http://dx.doi.org/10.4028/www.scientific.net/AMR.512-515.1923

Li, Z., Wu, D., Lv, W., Kang, S., \& Zheng, Z. (2013). Effect of Rare Earth Elements on Machining Characteristics of Austenitic Stainless Steels without Lead Addition. Advanced Materials Research, 377, 128-132.

Maekawa, K., Kubo, A., \& Childs, T. H. C. (2001). A Friction model for free-machining steels and its applicability to machinability analysis. Key Engineering Materials, 196, $79-90$. http://dx.doi.org/10.4028/www.scientific.net/KEM.196.79 
Panfilov, A. M., Lyamkina, N. S., Sotnikov, A. I., \& Zinovkin, A. A. (2002). A Setup for Viscosity Measurements of Oxide Melts by the Stokes Method. Instruments and Experimental Techniques, 45(1), 135-137. http://dx.doi.org/10.1023/A:1014585201031

Reh, B., Finger, U., Voight, W., \& Schultz, W. (1982). Neuere Erkenntnisse bei der Entwicklung von Hochleistungsautomatenstahl. Neue Hütte, 4, 121-124.

Reh, B., Voight, W., Finger, U., \& Schultz, W. (1979). Entwicklung eines microlegierten Automatenstahles. Neue Hütte, 12, 451.

Ryabov, A. V., \& Chumanov, I. V. (2012). Study and Possibility of Making New Easy-to-Cut Corrosion-Resistant Steel. Russian Metallurgy (Metally), 12, 1065-1067. http://dx.doi.org/10.1134/S0036029512120117

Shinozuka, J., Yachi, H., Higashi, T., Sando, M., Maetani, T., Unami, S., \& Ozaki, Y. (2012). Effect of MnS on the cutting mechanism of powder metallurgy steel in cutting speeds ranging from $1 \mathrm{~m} / \mathrm{s}$ to $150 \mathrm{~m} / \mathrm{s}$. Advanced Materials Research, 565, 370-375. http://dx.doi.org/10.4028/www.scientific.net/AMR.565.370

Shu, M. H., Chen, P. J., Hsu, B. M., Nguyen, T. L., Yeh, J. H., Lam, T. H., \& Lin, T. H. (2014). Optimization of sulfur-free-cutting steelmaking variables: six sigma-based approaches. Applied Mechanics and Materials, 470, 425-428. http://dx.doi.org/10.4028/www.scientific.net/AMM.470.425

Wei, Y. Y., Liu, Z. Q., An, Q. L., \& Chen, M. (2012). Study on the machinability of free-cutting steels 1214 and 12L15 with coated tool. Advanced Materials Research, 426, 151-154. http://dx.doi.org/10.4028/www.scientific.net/AMR.426.151

Wu, D., \& Li, Z. (2012). Study on the Machinability of Free Cutting Non-Lead Austenitic Stainless Steels. Advanced Materials Research, 306-309. http://dx.doi.org/10.4028/www.scientific.net/AMR.430-432.306

Xu, J., An, Q., \& Chen, M. (2012). Experimental Study on High-speed Turning of Free-cutting Steel AISI 12L14 Using Multi-layer Coated Carbide Tools. Advanced Materials Research, 500, 3-7. http://dx.doi.org/10.4028/www.scientific.net/AMR.500.3

Young, N. O., Goldstein, J. S., \& Block, M. J. (1959). Speeding up thermocapillary migration of a confined bubble by wall slip. J. Fluid. Mech., 6, 350-356. http://dx.doi.org/10.1017/S0022112059000684

Zaslavskii, A. Y. (2005).Modern free-cutting steels. Composition, inclusions, properties. Chelyabinsk, South Ural State Univ. Publ., 206.

Zhang, T. (2013). Effective, Controlled Method to Add Sulfur into Molten Steel to Produce Free Cutting Steel for Automobile. Applied Mechanics and Materials, 364, 558-562. http://dx.doi.org/10.4028/www.scientific.net/AMM.364.558

Zhang, Y., Han, J., \& Wang, H. (2012). Graphitization Kinetic of Hypoeutectoid Graphitized Free Cutting Steel. Advanced Materials Research, 143-144, 508-511. http://dx.doi.org/10.4028/www.scientific.net/AMR.466-467.508

\section{Copyrights}

Copyright for this article is retained by the author(s), with first publication rights granted to the journal.

This is an open-access article distributed under the terms and conditions of the Creative Commons Attribution license (http://creativecommons.org/licenses/by/3.0/). 